\title{
Two new species of the Euxoa westermanni species-group from Canada (Lepidoptera, Noctuidae, Noctuinae)
}

\author{
J. Donald Lafontaine ${ }^{1, \dagger}$, James T. Troubridge $e^{2, \ddagger}$ \\ I Canadian National Collection of Insects, Arachnids, and Nematodes, Biodiversity Program, Agriculture and \\ Agri-Food Canada, KW Neatby Bldg., C.E.F., Ottawa, Ontario, Canada K1A 0C6 2 Selkirk, Ontario, Ca- \\ nada, NOA 1 PO \\ † urn:lsid:zoobank.org:author:2227A860-B768-4A51-8FE4-F1F3EB1CAA7F \\ † urn:lsid:zoobank.org:author:F4E8E42C-3E05-4B00-A57C-C2DF5F11E750 \\ Corresponding authors: J. Donald Lafontaine (Don.Lafontaine@agr.gc.ca), James T. Troubridge (jtt@pri- \\ mus.ca) \\ Academic editor: Christian Schmidt | Received 26 December 2009| Accepted 20 January 2010 | Published 18 March 2010 \\ urn:lsid:zoobank.org:pub:35674C9E-AA00-4C5A-9751-31D0CCFBA50E \\ Citation: Lafontaine JD, Troubridge JT (2010) Two new species of the Euxoa westermanni species-group from Canada \\ (Lepidoptera, Noctuidae, Noctuinae). In: Schmidt BC, Lafontaine JD (Eds) Contributions to the systematics of New \\ World macro-moths II. ZooKeys 39: 255-262. doi: 10.3897/zookeys.39.436
}

\begin{abstract}
Two new species of Euxoa Hübner are described from northern and western Canada: Euxoa apopsis Troubridge \& Lafontaine, related to E. macleani McDunnough, and E. muldersi Lafontaine \& Hensel, related to E. churchillensis McDunnough. Euxoa chimoensis Hardwick, stat. rev., is recognized as a valid species rather than as a subspecies of Euxoa macleani. A diagnosis of the E. westermanni species-group is given with descriptions and illustrations of the new species and their relatives.
\end{abstract}

\section{Keywords}

Systematics, Canada, Euxoa, Euxoa westermanni species-group

Copyright Authors. This is an open access article distributed under the terms of the Creative Commons Attribution License, which permits unrestricted use, distribution, and reproduction in any medium, provided the original author and source are credited. 


\section{Introduction}

The genus Euxoa Hübner was revised as a "Moths of America North of Mexico" volume by Lafontaine (1987) and included 180 species. Since that time two undescribed species of the Euxoa westermanni species-group (subgenus Pleonectopoda Grote) have been found in northern and western Canada. In addition, many additional specimens of Euxoa chimoensis Hardwick have been collected in northeastern and central Canada that show this it is a valid species, not a subspecies of Euxoa macleani, which occurs in western Canada. In 1987, Euxoa chimoensis was known only from male specimens and Euxoa macleani from only five males and a female. The two new species and Euxoa chimoensis Hardwick are described below.

\section{Materials and methods}

Specimens were examined from the following collections:

AMNH American Museum of Natural History, New York, NY, USA

BMNH Natural History Museum, London, UK

CNC Canadian National Collection of Insects, Arachnids, and Nematodes, Ottawa, Ontario, Canada.

HHC Personal collection of Henry Hensel, Edmundston, New Brunswick, Canada. JTTC Personal collection of James Troubridge, Selkirk, Ontario, Canada.

USNM National Museum of Natural History, Washington, District of Columbia, USA.

Dissecting methods and genital terminology. Dissection of genitalia and terms for genital structures and wing markings follow Lafontaine (2004).

\section{Systematics}

\section{Euxoa westermanni species-group}

The Euxoa westermanni species-group is included in the subgenus Pleonectopoda Grote, one of seven subgenera of Euxoa (Lafontaine 1987). The E. westermanni species-group is the largest of the six species-groups in the subgenus, and includes 20 of the 27 species in the subgenus. It is the only species-group in the subgenus Pleonectopoda Grote that occurs in the Palearctic.

Species in the E. westermanni species-group are best characterized by the male genitalia: the vesica has a subbasal coil (like other species in subgenus Pleonectopoda), the medial diverticulum is closer to the subbasal coil of the vesica than the apex, the subbasal diverticulum is bilobed, and the saccular extensions are short, shorter than the clasper and about $1 / 3 \times$ as long as the valve. 
Most species of the E. westermanni species-group occur in subarctic, alpine, and subalpine habitats and they dominate the Euxoa fauna in these areas. Six species are associated with dunes and open sandy habitats, three in the subarctic (E. hyperborea Lafontaine, 1987, E. churchillensis (McDunnough, 1932), and E. muldersi Lafontaine $\&$ Hensel, sp. n.) and three farther south in Canada and northern United States (E. scandens (Riley, 1869), E. quebecensis (Smith, 1900), and E. aurulenta (Smith, 1890)).

One of the species described below is associated with open dunes in northern Canada; the other occurs in alpine areas in western British Columbia.

\section{Descriptions}

\section{Euxoa muldersi Lafontaine \& Hensel, sp. n.} urn:lsid:zoobank.org:act:13A91C23-B4CC-426C-B961-9E0066029FD8 Figs 1-4, 19, 24

Type material. Holotype ${ }^{\top}$ : Canada, Nunavut: Austin Island, Maguse Point, $29 \mathrm{~km}$ $\mathrm{N}$ of Arviat, 12 July 1996, H. Hensel \& R. Mulders [CNC]. Paratypes 38 ${ }^{\lambda}, 13$ : same locality as for holotype; 26 July 1992, R. Mulders; 12, 16 July 1996, H. Hensel \& R. Mulders; 18 July 1996, H. Hensel; 7, 8 July 1998, H. Hensel; 17 July 2000, H. Hensel; vicinity of Arviat, 11, 12 July 1998, H. Hensel; 18-27 July 2000, H. Hensel; 16-22 July 2002, H. Hensel. BMNH, CNC, HHC, JTTC, USNM, and personal collection Hartmut Rietz, Hamburg, Germany.

Other material examined. Canada. Canada, Northwest Territories, Ford Lake, $63^{\circ} 11^{\prime} \mathrm{N} 107^{\circ} 19$ W, 25 June 1966, G. E. Shewell (2仓̂).

Etymology. The species is named for Robert Mulders, a biologist at Arviat who collected the first specimen and brought it to the attention of Henry Hensel.

Diagnosis. In the key to species of the Euxoa westermanni species-group in Lafontaine (1987) E. muldersi keys out to Euxoa churchillensis McDunnough. It differs from E. churchillensis (Figs 5-7, 20, 25) in larger size (forewing length $13-15 \mathrm{~mm}$ versus $10-13 \mathrm{~mm}$ in E. churchillensis), more blurry forewing pattern usually with brown shading, basally paler more mottled hindwing, reduced, vestigial frontal tubercle, shorter, stouter saccular extension and straight sub-basal diverticulum (curved in E. churchillensis) in the male genitalia (compare Figs 19 and 20). In females, the anal papillae are broad and more rounded compared to bullet-shaped in E. churchillensis.

Description. Adult: Head - Frontal tubercle vertically elongated but small, low, only slightly raised from frons; male antenna slightly biserrate, about $1.3 \times$ as wide as shaft; eye reduced, ellipsoid, with sparse surface hair; vestiture of head and thorax a highly variable mixture of buff, brown, and black hair-like and strap-like scales, usually covering frontal tubercle. Thorax - Legs: tibia with spiniform setae typical for Euxoa. Wings (both sexes); most common form (Fig. 1 [80\% of specimens]) ground color a variable mixture of pale-gray, brown, and black scales, usually with darker colors 
predominating in medial area; basal dash and antemedial and postmedial lines black but diffuse and appearing blurry; terminal area dark gray to black with diffused streaks extending into subterminal area; reniform and orbicular pale gray, sometimes with

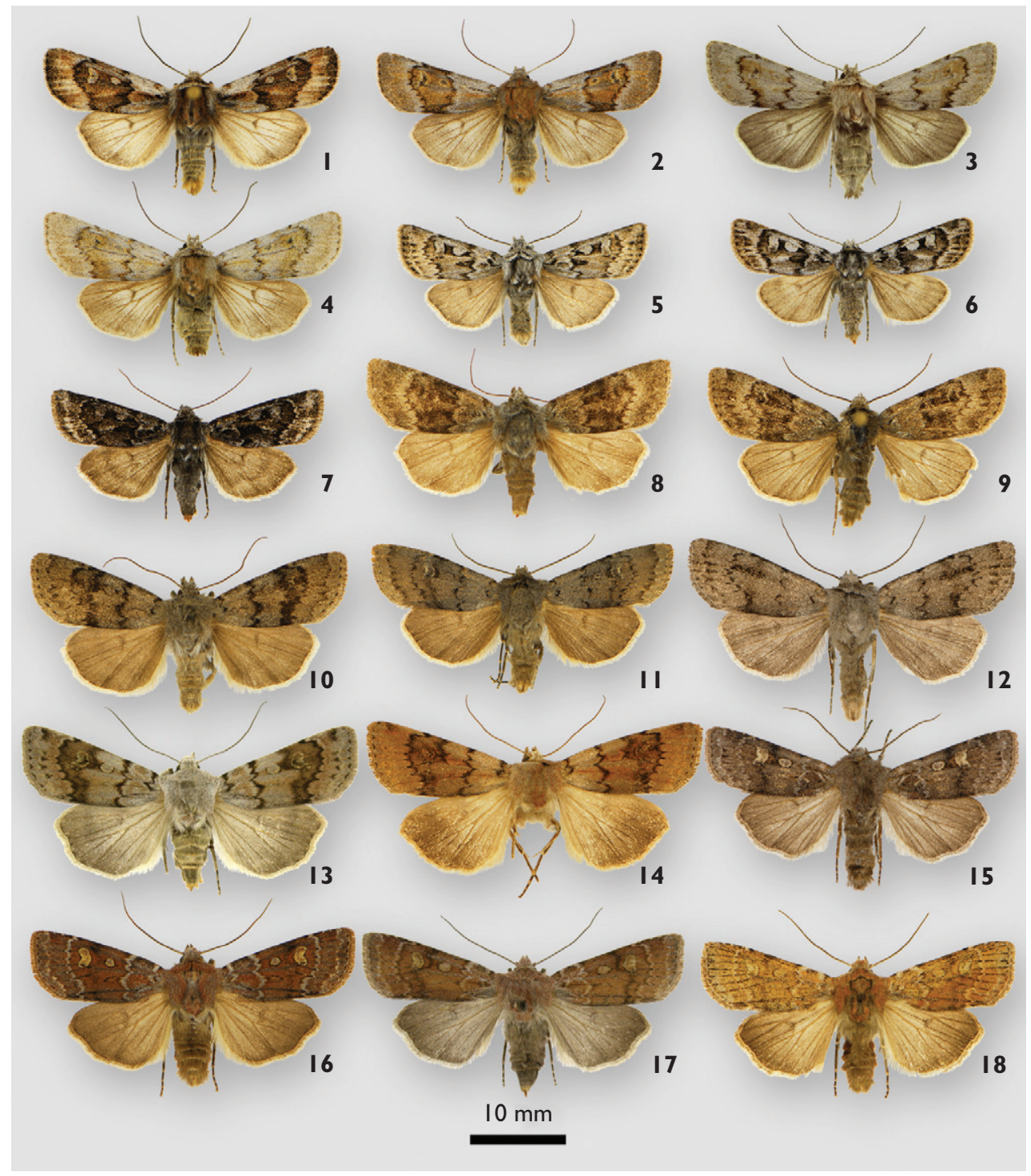

Figures I-1 8. Euxoa adults. I-4 E. muldersi, I $\delta$ holotype $2 \delta$ paratype, Maguse Point, Austin Island, $29 \mathrm{~km} \mathrm{~N}$ of Arviat, Nunavut, Canada 3 + 4 q paratypes, Maguse Point, Austin Island, $29 \mathrm{~km} \mathrm{~N}$ of Arviat, Nunavut, Canada; 5-7 E. churchillensis, $\mathbf{5}$ đ $\mathbf{6} 7$ 7 , Arviat, Nunavut, Canada; 8, 9 E. apopsis, 8 paratype, Mt. McLean, British Columbia, Canada 9 đ holotype, Gott Peak, 7100’, British Columbia, Canada; 10-12 2 E. macleani, Gott Peak, 7100', British Columbia, Canada; 13-18 E. chimoensis,

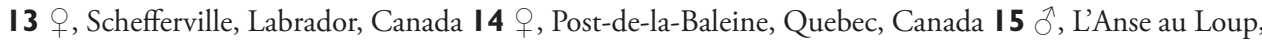

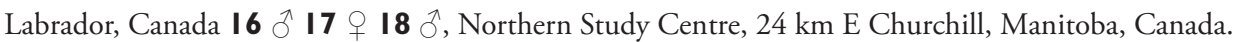


darker outline and darker central spot; paler form (Fig. 2 [10\% of specimens]) with less brown shading and less mottling of ground color; dark shading in reniform spot filling most of spot; pale form (Figs 3, 4 [10\% of specimens]) mainly pale gray with blurry dark-gray transverse lines and reniform spot. Hindwing dirty white mottled with fuscous shading, especially on outer half of wing, postmedial line, and discal spot; fringe white. Male genitalia - Similar to those of E. churchillensis in most details except saccular extension shorter and slightly stouter $(0.54-0.58 \times$ as long as ampulla of clasper (harpe) versus $0.60-0.68 \times$ as long in E. churchillensis); subbasal diverticulum in vesica straight (curved in E. churchillensis). Female genitalia - Similar to those of $E$. churchillensis but anal papillae broad and more rounded in lateral view (bullet shaped in E. churchillensis).

Distribution and biology. Euxoa muldersi is known only from north central Canada with all specimens except two from the vicinity of Arviat, Nunavut. The species must use a similar pheromone to E. churchillensis because $\mathrm{H}$. Hensel observed males of E. churchillensis being attracted to calling $E$. muldersi females, although no attempts at mating were observed. It is restricted to open dunes where it flies close to the sand. The reduced frontal tubercle is typical of Euxoa species that inhabit dunes.

\section{Euxoa apopsis Troubridge \& Lafontaine, sp. $\mathbf{n}$.} urn:Isid:zoobank.org:act:546F2D15-D536-468D-8D5E-D3C254C7D09B Figs 8, 9, 21, 26

Type material. Holotype ${ }^{\top}$ : Canada, British Columbia: Gott Peak, $7100^{\prime}, 50^{\circ} 21^{\prime} \mathrm{N}$ $122^{\circ} 08^{\prime} \mathrm{W}, 12$ July 1992, J. Troubridge [CNC]. Paratypes $1 \hat{0}^{\hat{\prime}}, 1$ 우: same data as for hol-

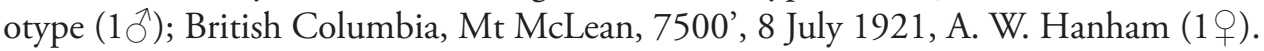

Etymology. The species name is a Greek noun used in apposition and means "a lofty spot," in reference to the high elevation of the type locality.

Diagnosis. In the key to species of the Euxoa westermanni species-group in Lafontaine (1987) E. apopsis keys out to Euxoa macleani McDunnough. It differs from $E$. macleani (Figs 10-12, 22, 27) in having a more deeply biserrate male antenna, more extensive dark shading on the medial line of the forewing, a paler hindwing, thinner saccular extensions and a smaller subbasal diverticulum in the male genitalia, and a smaller appendix bursae in the female genitalia.

Description. Adult: Head - Frontal tubercle prominent and rounded; male antenna deeply biserrate, $2.0 \times$ as wide as shaft $(1.5 \times$ as wide in E. macleani); eye reduced, ellipsoid; vestiture of head and thorax mainly of dark gray hair-like and strap-like scales with some white scales and some white-tipped scales. Thorax - Legs: tibia with spiniform setae typical for Euxoa. Wings (both sexes); ground color gray with scattered white and dark-gray scales that give wing a grizzled look; basal area medium gray; medial area extensively shaded with dark gray; subterminal area pale gray with dark-gray streaks in outer part of subterminal area; terminal area similar in color to basal area; antemedial $(\mathrm{am})$ and postmedial $(\mathrm{pm})$ lines black with pale-gray shading proximal to 


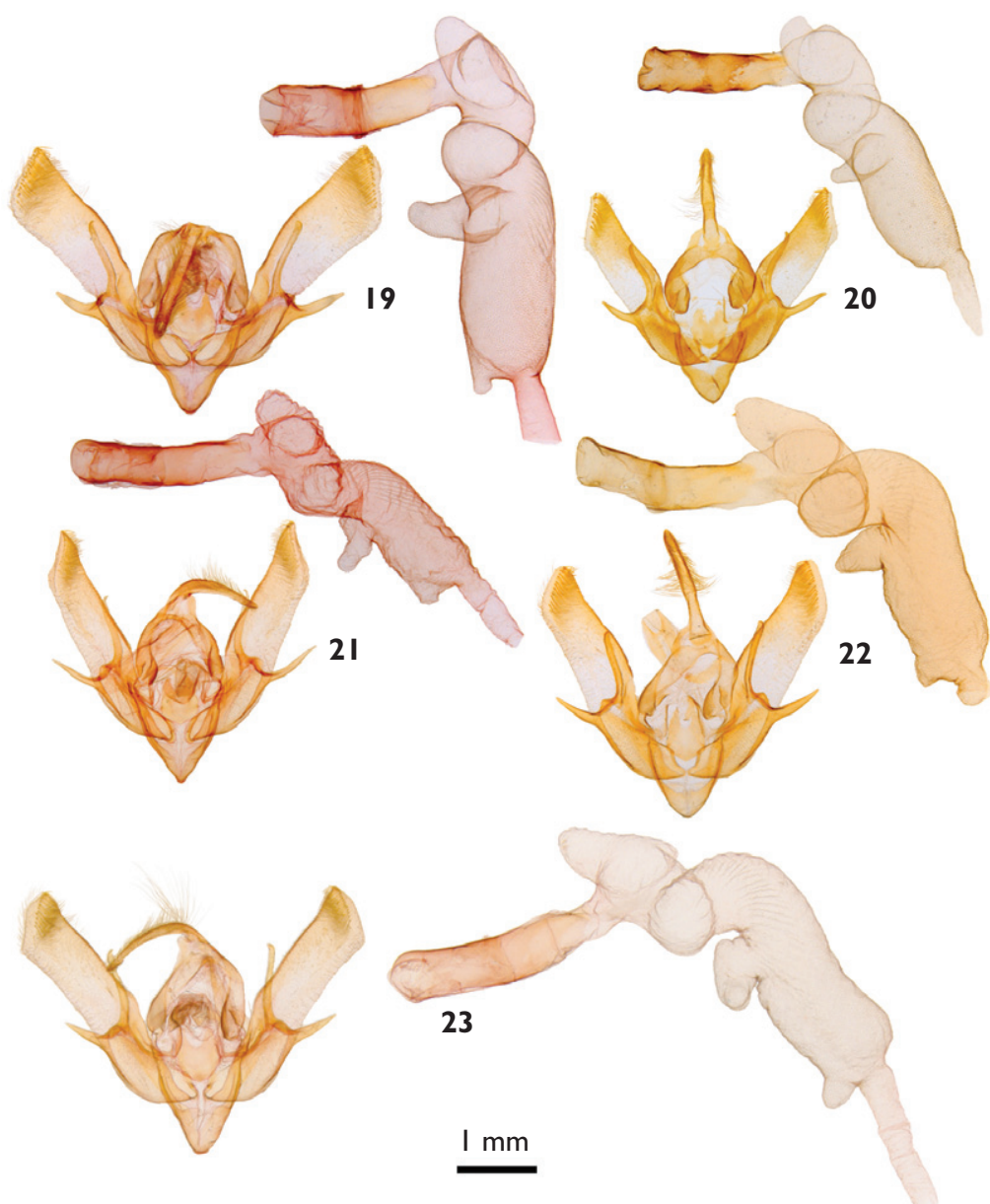

Figures 19-23. Euxoa male genitalia. 19 E. muldersi $\mathbf{2 0}$ E. churchillensis $\mathbf{2 1}$ E. apopsis $\mathbf{2 2}$ E. macleani 23 E. chimoensis.

am line and distal to pm line; reniform and orbicular spots paler than medial area but small and obscure; forewing length: $14-15 \mathrm{~mm}$ (14-18 $\mathrm{mm}$ in E. macleani). Hindwing pale fuscous gray with darker veins and discal spot; fringe yellowish buff basally, white distally. Male genitalia - Similar to those of E. macleani in most details except saccular extensions thinner than ampulla of clasper (harpe) (stouter in E. macleani); subbasal diverticulum in vesica shorter, $2.0 \times$ as wide as aedeagus $(2.5 \times$ as wide in E. macleani). Female genitalia - Similar to those of $E$. macleani but appendix bursae smaller, $0.5 \times$ as long as corpus bursae $(0.7 \times$ as long in $E$. macleani).

Distribution and biology. Euxoa apopsis is known only from high elevations in the mountains of southwestern British Columbia. Adults may be partially diurnal, which may explain why only two specimens were collected at the type locality in spite of many nights of collecting over a period of six years. 


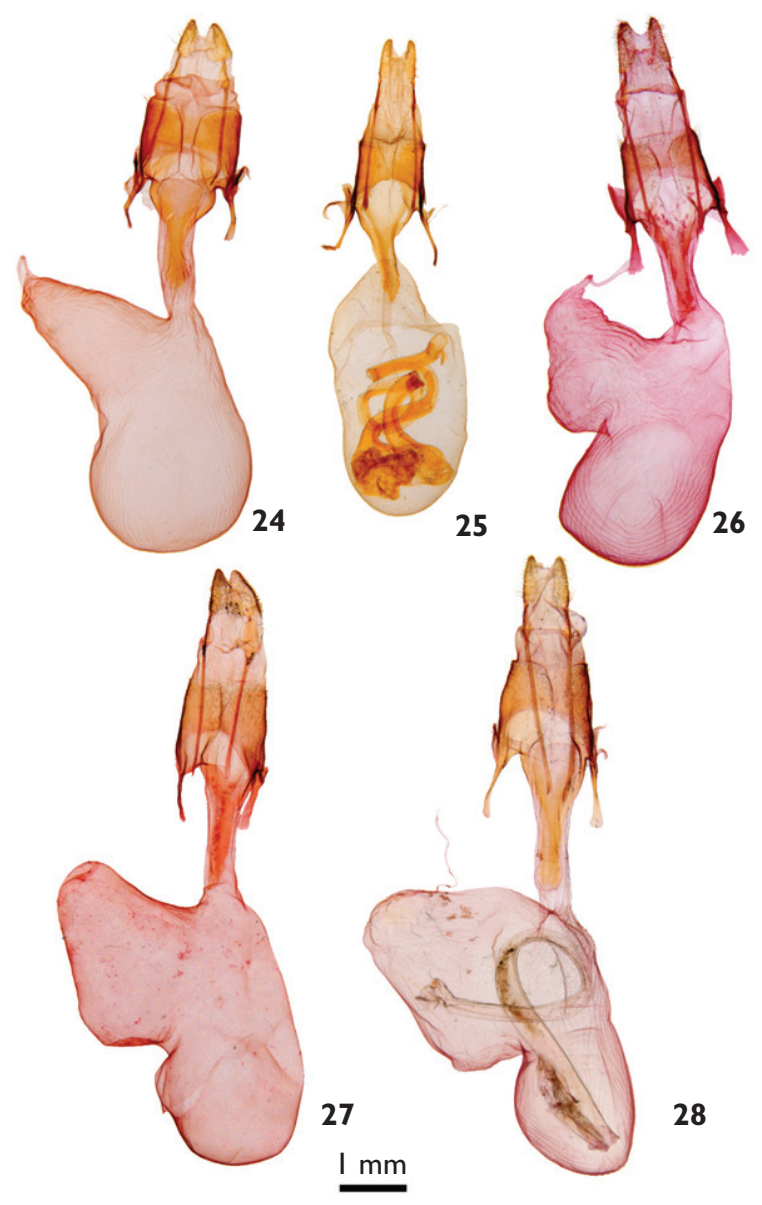

Figures 24-28. Euxoa female genitalia. $\mathbf{2 4}$ E. muldersi $\mathbf{2 5}$ E. churchillensis $\mathbf{2 6}$ E. apopsis $\mathbf{2 7}$ E. macleani 28 E. chimoensis.

\section{Euxoa chimoensis Hardwick, stat. rev.}

Figs 13-18, 23, 28

Diagnosis. This species was treated as a subspecies of Euxoa macleani in Lafontaine (1987). Unlike Euxoa macleani, which occurs only as a single form (Figs 10-12) with a dark brownish-gray forewing with most maculation obscure except for black transverse lines and medial line, E. chimoensis occurs in three color forms with two pattern forms. The forewing may be reddish brown, blackish brown or gray. For each of these color forms the forewing occurs in two pattern forms; in one form (Figs 13, 14) the transverse lines are prominent and the reniform and orbicular spots are similar to the ground color or darker; in the second form (Figs 15-18) the transverse lines and or- 
bicular and reniform spots appear mainly paler than the ground color; both of these forms seem to be equally common in Quebec and Labrador, but only the form with pale markings is known from the west coast of Hudson Bay. Forewing length varies from 13 to $17 \mathrm{~mm}$. The male and female genitalia (Figs 23, 28) are similar to those of E. macleani (Figs 22, 27), but the appendix bursae in E. chimoensis projects mainly to the left, whereas in that of E. macleani has a lobe of the appendix bursae that projects posteriorly giving the appendix a longitudinal orientation.

Distribution and biology. Euxoa chimoensis is known only from two localities in Labrador, three in Quebec, and one in Manitoba, but these are widely scattered and indicate that the species is widely distributed in Labrador and northern Quebec and along the west coast of Hudson Bay. Adults have been collected throughout July.

\section{Acknowledgments}

We thank Jocelyn Gill (CNC, Ottawa) for assistance with the preparation of the genitalia and photographs. Paul Hebert and the staff at the Canadian Centre for DNA Barcoding, Biodiversity Institute of Ontario, University of Guelph, Guelph, Canada, provided data and information from the Barcode of Life Data (BOLD) system. Gary Anweiler and Chris Schmidt reviewed the manuscript and provided many helpful suggestions.

\section{References}

Lafontaine JD (1987) Noctuoidea Noctuidae (part) Noctuinae (part - Euxoa). In: Dominick $\mathrm{RB}$ et al. (Eds) The Moths of America north of Mexico, fasc. 27.2. The Wedge Entomological Research Foundation, Washington, DC, 237 pp.

Lafontaine JD (2004) Noctuoidea, Noctuidae (part), Noctuinae (part - Agrotini). In: Hodges RW (Ed) The Moths of North America, fasc. 27.1. The Wedge Entomological Research Foundation, Washington, 385 pp. 